\title{
Blood eosinophils and inhaled corticosteroids in patients with COPD: systematic review and meta-analysis
}

This article was published in the following Dove Press journal: International Journal of COPD

\author{
Shih-Lung Cheng ${ }^{1,2}$ \\ 'Department of Internal Medicine, \\ Far Eastern Memorial Hospital, Taipei, \\ Taiwan; ${ }^{2}$ Department of Chemical \\ Engineering and Materials Science, \\ Yuan-Ze University, Taoyuan, Taiwan
}

Correspondence: Shih-Lung Cheng Department of Internal Medicine, Far Eastern Memorial Hospital, 2I Nanya South Road, Taipei, Taiwan Tel +8862 89667000 ext 2160 Fax +886277380708

Email shihlungcheng@gmail.com
Background: COPD is a highly heterogeneous disease. Potential biomarkers to identify patients with COPD who will derive the greatest benefit from inhaled corticosteroid (ICS) treatment are needed. Blood eosinophil count can serve as a predictive biomarker for the efficacy of ICS treatment. The aim of this systematic review and meta-analysis was to assess whether a blood eosinophil count of $\geq 2 \%$ in patients undergoing ICS therapy was associated with a greater reduction in COPD exacerbation rate and pneumonia incidence.

Materials and methods: An electronic search was performed using the keywords "COPD", "eosinophil", and "clinical trial" in the PubMed and EMBASE databases to retrieve articles, up to 2017, relevant to our focus. Data were extracted, and a meta-analysis was conducted using RevMan 5 (version 5.3.5).

Results: Five studies comprising 12,496 patients with moderate-to-very severe COPD were included. At baseline, $60 \%$ of the patients had $\geq 2 \%$ blood eosinophils. Our meta-analysis showed a $17 \%$ reduction in exacerbation of moderate/severe COPD in patients with $\geq 2 \%$ blood eosinophils undergoing ICS therapy compared to the non-ICS/ICS withdrawal/placebo group. The difference between the two types of treatment was significant (risk ratio [RR], 0.816; 95\% CI, 0.67-0.99; $P=0.03$ ). Furthermore, the risk of pneumonia-related events was significantly increased in the subgroup with eosinophil count $\geq 2 \%$ undergoing ICS-containing treatments (RR, 1.969; 95\% CI, 1.369-2.833; $P<0.001)$. There was no significant difference in the subgroup with eosinophil count $<2 \%$ (RR, 1.29; 95\% CI, 0.888-1.879; $P<0.181$ ).

Conclusion: The results of our meta-analysis suggest that the $2 \%$ threshold for blood eosinophils could accurately predict ICS treatment response in patients with COPD, but increased the risk of pneumonia.

Keywords: COPD, inhaled corticosteroid, eosinophil

\section{Introduction}

Inhaled corticosteroids (ICSs) can reduce acute exacerbation in patients with COPD having moderate-to-very severe lung function defects and a history of frequent exacerbation. ${ }^{1-5}$ However, the risks and benefits of ICS treatment are still controversial, especially the purported increase in pneumonia incidence. ${ }^{6}$ Airway eosinophilia is a hallmark inflammatory response for asthma pathogenesis and is now known to be involved in the airway inflammatory process in COPD. ${ }^{7-9}$ Eosinophilic COPD is defined using sputum eosinophil counts of $\geq 3 \%$ and has been reported during acute exacerbations in up to $28 \%$ of cases. ${ }^{10}$ Interestingly, it is seen in $\sim 34 \%{ }^{11}$ (or $38 \%{ }^{12}$ ) of patients with COPD in stable condition. Airway eosinophilia is an important marker 
for treatment effectiveness of inhaled and oral corticosteroid therapies in patients with COPD. ${ }^{12-15}$

A diagnostic tool for the measurement and detection of airway eosinophilia is induced sputum assessment. ${ }^{8}$ Sputum induction is thought to be a direct and reliable method for evaluating airway inflammation; however, it has several limitations. ${ }^{16,17}$ For instance, it is unsuitable for point-of-care testing, requires experience, and has a failure rate of up to $30 \% .^{16,17}$ Due to these limitations, the search for minimally invasive and easily available methods that can identify and evaluate the status of sputum eosinophilia inflammation in asthma and COPD has been intensified. ${ }^{10,11,18-21}$ The use of peripheral blood cell counts is a simple and attractive tool that has potential in clinical practice. The prediction and accuracy of blood eosinophils and sputum eosinophilia in patients with asthma have been assessed and have demonstrated promising results. ${ }^{21-24}$ However, limited studies have examined this issue in patients with COPD in a stable condition. One study reported a correlation between bronchial and blood eosinophil counts in 20 patients with COPD and 21 healthy controls. ${ }^{25}$ Previous reports have also confirmed that blood eosinophils can serve as a good biomarker for steroid therapy in exacerbating ${ }^{26}$ and stable ${ }^{27,28}$ patients with COPD. Therefore, blood eosinophil count could be a predictive biomarker to indicate stable or exacerbating status and may indicate the effectiveness of ICS treatment in patients with COPD.

At present, there is still a lack of consensus about the optimal threshold of blood eosinophils for guiding ICS treatment in patients with stable COPD. Hence, the aim of this systematic review and meta-analysis was to investigate the predictive value of blood eosinophil count (cutoff point of $2 \%$ ) as a biomarker of ICS efficacy in reducing the annual rate of moderate/severe exacerbations for patients with moderateto-very severe COPD and a history of exacerbations.

\section{Materials and methods}

\section{Search strategy and inclusion/exclusion criteria}

This systematic review was performed in accordance with the guidelines on "Systematic Reviews and Meta-analysis: Understanding the Best Evidence in Primary Healthcare" and "How to Review a Meta-analysis". A comprehensive search was conducted using the terms "COPD", "eosinophil", and "clinical trial" in PubMed and EMBAS to identify relevant studies published up to 2017. All articles identified in the initial database search were screened based on title, abstract, and full text to confirm eligibility and avoid overlapping data. Primary research articles were compared for the following items: studies of ICS treatment and annual rates of moderate/severe exacerbations in patients with COPD with $<2 \%$ and $\geq 2 \%$ blood eosinophils. Studies involving patients with COPD that had acute exacerbation, preclinical studies, and conference abstracts were excluded from our meta-analysis.

\section{Data extraction}

Relevant data were extracted from the eligible publications: the name of the first author, the year of publication, trial name, the number of patients analyzed, inclusion criteria for participants, baseline patient characteristics, treatment regimens, study duration, the annual rate of moderate/severe exacerbations (including time-to-first exacerbations), and pneumonia events. Data on the therapeutic partners for ICS medications were obtained from seven studies from 1 to 3 years. The therapeutic partners included fluticasone propionate, fluticasone furoate, salmeterol+tiotropium, and ICS+long-acting $\beta 2$-agonist (LABA).

\section{Statistical analysis}

To compare patients with COPD with eosinophil counts of $<2 \%$ and $\geq 2 \%$ in terms of the risk of exacerbation, time-of-first exacerbation, and pneumonia events, the metaanalysis software, "Comprehensive Meta-Analysis" version 2.2.055 (Englewood, NJ, USA) was used. Heterogeneity across studies was assessed by the Cochran's Q statistic test and the $I^{2}$ test. $I^{2}$ values $\geq 25 \%, 50 \%$, and $75 \%$ were considered to reflect mild, moderate, and high degrees of heterogeneity, respectively. A random-effects model was used for pooled outcome measures with $I^{2}>50 \%$. The difference in moderate/severe exacerbation rate between both treatment arms was expressed as the risk ratio (RR). The time-to-first exacerbation was expressed as the hazard ratio (HR). The relative risk of pneumonia events was expressed as RR. Data are presented as 95\% CIs.

\section{Results}

\section{Search strategy and data extraction}

From the search using the keywords "COPD", "eosinophil", and "clinical trial" from PubMed and EMBASE, a total of 57 primary articles that were potentially relevant were obtained to determine further eligibility. Of these, 52 articles did not fulfill our inclusion criteria and were excluded. Of the five remaining publications ${ }^{27,29-32}$ published from 2015 to 2016 , a total of 12,496 patients were included in this metaanalysis/systematic review. The characteristics of the eligible studies are summarized in Table 1. Overall, the total number 
Table I Summary of five articles from PubMed and EMBASE that were determined eligible using the keywords "COPD”, "eosinophil”, and "clinical trial" based on systematic review criteria

\begin{tabular}{|c|c|c|c|c|c|}
\hline No & Author & Year & Title & Study arms & Subgroup \\
\hline I & Barnes et $\mathrm{al}^{29}$ & 2016 & Blood eosinophils as a marker of response to ICS in COPD & FP vs placebo & $\begin{array}{l}\text { Eos count: } \\
<2 \% \text { and } \geq 2 \%\end{array}$ \\
\hline 2 & Pascoe et $\mathrm{al}^{27}$ & \multirow[t]{3}{*}{2015} & $\begin{array}{l}\text { Blood eosinophil counts, exacerbations, and response to the } \\
\text { addition of inhaled fluticasone furoate to vilanterol in patients } \\
\text { with COPD: a secondary analysis of data from two parallel } \\
\text { randomised controlled trials }\end{array}$ & FP/SAL vs tiotropium & \multirow[t]{3}{*}{$\begin{array}{l}\text { Eos count: } \\
<2 \% \text { and } \geq 2 \%\end{array}$} \\
\hline & $\begin{array}{l}\text { coe et al } 2015 \\
\text { (appendix) }\end{array}$ & & \multicolumn{2}{|c|}{ FP/SAL with its monocomponents and placebo } & \\
\hline & Appendix & & \multicolumn{2}{|l|}{ FP/SAL with FP and placebo } & \\
\hline 3 & Pascoe et $\mathrm{al}^{27}$ & 2015 & $\begin{array}{l}\text { Blood eosinophil counts, exacerbations, and response to the } \\
\text { addition of inhaled fluticasone furoate to vilanterol in patients } \\
\text { with COPD: a secondary analysis of data from two parallel } \\
\text { randomised controlled trials }\end{array}$ & $\begin{array}{l}\text { Fluticasone furoate }+ \\
\text { vilanterol vs vilanterol } \\
\text { alone }\end{array}$ & $\begin{array}{l}\text { Eos count: } \\
<2 \% \text { and } \geq 2 \%\end{array}$ \\
\hline 4 & Roche et $\mathrm{al}^{32}$ & 2017 & $\begin{array}{l}\text { Blood eosinophils and response to maintenance COPD } \\
\text { treatment }\end{array}$ & $\begin{array}{l}\text { Indacaterol } \\
\text { glycopyrronium vs } \\
\text { fluticasone salmeterol }\end{array}$ & $\begin{array}{l}\text { Eos count: } \\
<2 \% \text { and } \geq 2 \% \\
<3 \% \text { and } \geq 3 \% \\
<5 \% \text { and } \geq 5 \%\end{array}$ \\
\hline 5 & Watz et $\mathrm{al}^{31}$ & 2016 & $\begin{array}{l}\text { Blood eosinophil count and exacerbations in severe COPD } \\
\text { after withdrawal of ICS: a post-hoc analysis of the WISDOM } \\
\text { trial }\end{array}$ & $\begin{array}{l}\text { ICS continuation vs } \\
\text { ICS withdrawal }\end{array}$ & $\begin{array}{l}\text { Eos count: } \\
<2 \% \text { and } \geq 2 \%\end{array}$ \\
\hline
\end{tabular}

Abbreviations: Eos, eosinophil; ICS, inhaled corticosteroid; FP, fluticasone propionate; SAL, salmeterol.

of patients included in our study was 12,496. All participants were current or ex-smokers with a mean age of 64 years and were diagnosed with moderate-to-vey severe COPD. The asthma diagnosis was excluded in all trials. The proportion of patients with $\geq 2 \%$ blood eosinophils at baseline ranged from $32 \%$ to $75 \%$ in seven studies (mean $60 \%$ ). In total, ICS-containing treatments included 854 patients treated with ICS monotherapy, 5,134 patients treated with ICS+LABA combination therapy; and 1,115 patients treated with ICS+LABA+long-acting muscarinic antagonist (LAMA) triple therapy. Non-ICS/ICS withdrawal/placebo included 4,269 patients treated with non-ICS regimens/placebo and 1,124 patients in withdrawal from ICS+LABA+LAMA triple therapy.

\section{Primary outcome: risk of moderate/ severe exacerbation}

In the meta-analysis of primary outcomes, seven studies s $^{27,29-32}$ were pooled for moderate/severe exacerbation RR analysis. Overall, there was no significant difference between ICScontaining treatments and non-ICS/ICS withdrawal/placebo treatments at eosinophil counts of $<2 \%$ (RR, 1.038; $95 \%$ CI, 0.882-1.222; $P=0.654$ ), as shown in Figure 1A. ICScontaining treatments in the subgroup with eosinophil counts of $\geq 2 \%$ had a significantly reduced RR of moderate/ severe exacerbations than did non-ICS/ICS withdrawal/ placebo treatment groups (RR, $0.816 ; 95 \%$ CI, 0.672-0.990;
$P=0.039$ ), as shown in Figure 1B. The publication bias of pooled risk for moderate/severe exacerbations was minimized by selecting high-quality articles and well-compared systematic review items, whereby either eosinophil counts of $<2 \%$ or $\geq 2 \%$ had a low risk difference (Figure 2 ).

\section{Secondary outcomes: risk of time-to- first moderate/severe exacerbation and pneumonia}

ICS-continuing treatment in patients with COPD with baseline blood eosinophil levels $\geq 2 \%$ was associated with reduced risk of moderate/severe exacerbation. The secondary outcomes of the meta-analysis (pooled HRs for time-to-first moderate/severe exacerbation and pooled relative risk of pneumonia events) were significantly higher in the subgroup with eosinophil counts $\geq 2 \%$ with ICS-containing treatments.

Two populations of five studies ${ }^{29,32}$ were pooled to analyze the HR for time-to-first moderate/severe exacerbation between ICS-containing treatments and non-ICS/ICS withdrawal/placebo treatments in the subgroup with eosinophil counts $<2 \%$, but no significant association was observed (HR, 1.148; 95\% CI, 0.743-1.775; $P=0.534$ ), as shown in Figure $3 \mathrm{~A}$. In the subgroup with eosinophil counts $\geq 2 \%$, ICS-containing treatments showed a significantly higher association with moderate/severe exacerbation than did non-ICS/ICS withdrawal/placebo treatments (HR, 1.173; 
A

Study name

Statistics for each study

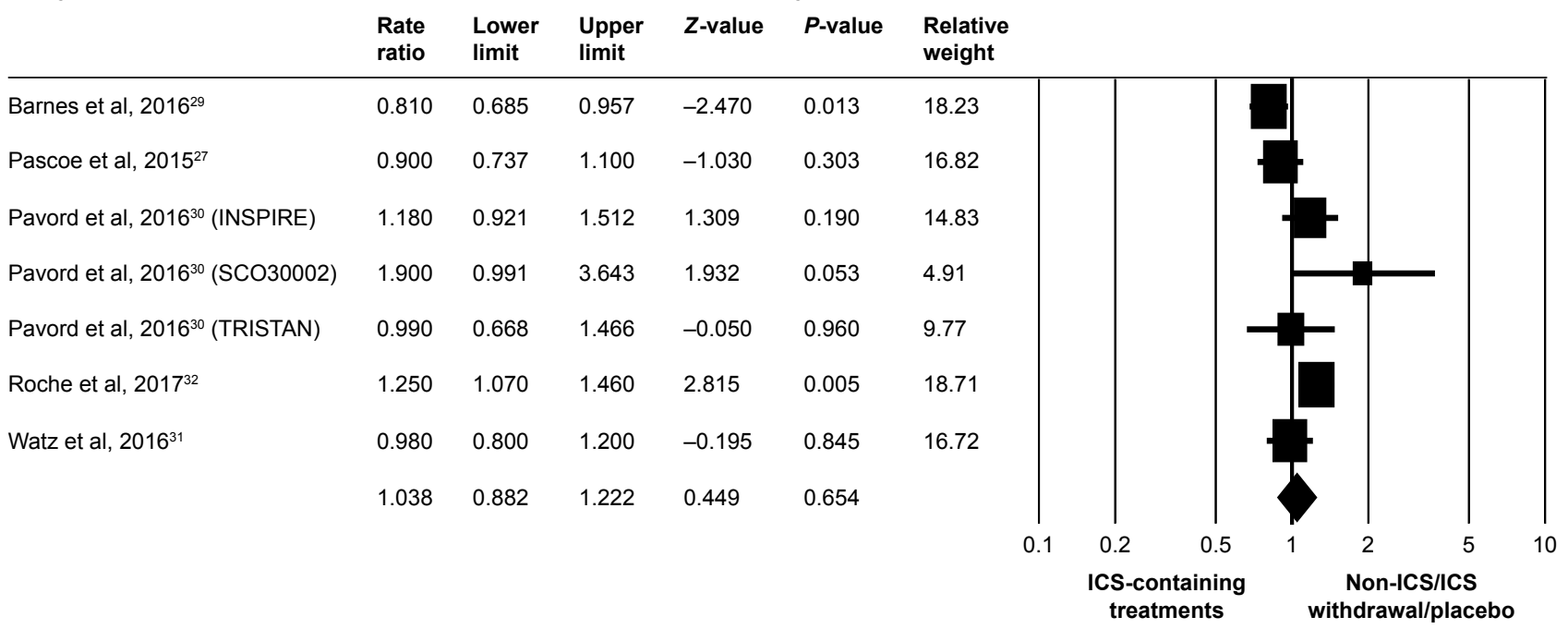

B

Study name

Statistics for each study

$\begin{array}{lllll}\text { Rate } & \text { Lower } & \text { Upper } & Z \text {-value } & P \text {-value } \\ \text { ratio } & \text { limit } & \text { limit }\end{array}$

Barnes et al, $2016^{29}$

Pascoe et al, $2015^{27}$

Pavord et al, 2016 30 (INSPIRE)

Pavord et al, $2016^{30}$ (SCO30002)

Pavord et al, $2016^{30}$ (TRISTAN)

Roche et al, $2017^{32}$

Watz et al, $2016^{31}$

$\begin{array}{llllll}0.880 & 0.694 & 1.116 & -1.054 & 0.292 & 14.23 \\ 0.710 & 0.612 & 0.823 & -4.538 & 0.000 & 16.39 \\ 0.750 & 0.606 & 0.929 & -2.638 & 0.008 & 14.84 \\ 0.820 & 0.480 & 1.400 & -0.727 & 0.467 & 7.59 \\ 0.630 & 0.501 & 0.792 & -3.959 & 0.000 & 14.46 \\ 1.170 & 1.035 & 1.323 & 2.502 & 0.012 & 16.89 \\ 0.820 & 0.683 & 0.984 & -2.129 & 0.033 & 15.60 \\ 0.816 & 0.672 & 0.990 & -2.060 & 0.039 & \end{array}$

Rate ratio and $95 \% \mathrm{Cl}$

Relative
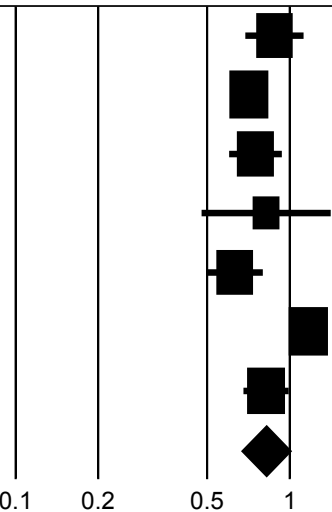

CS-containing treatments
Rate ratio and $95 \% \mathrm{CI}$

withdrawal/placebo 
A

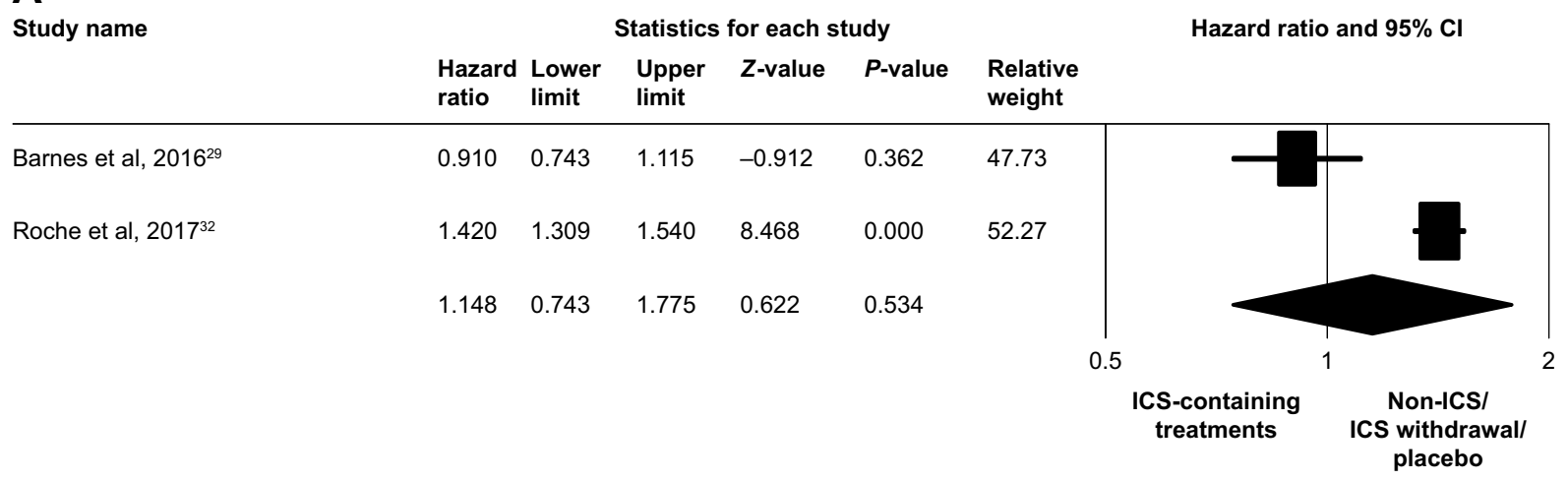

B

Study name

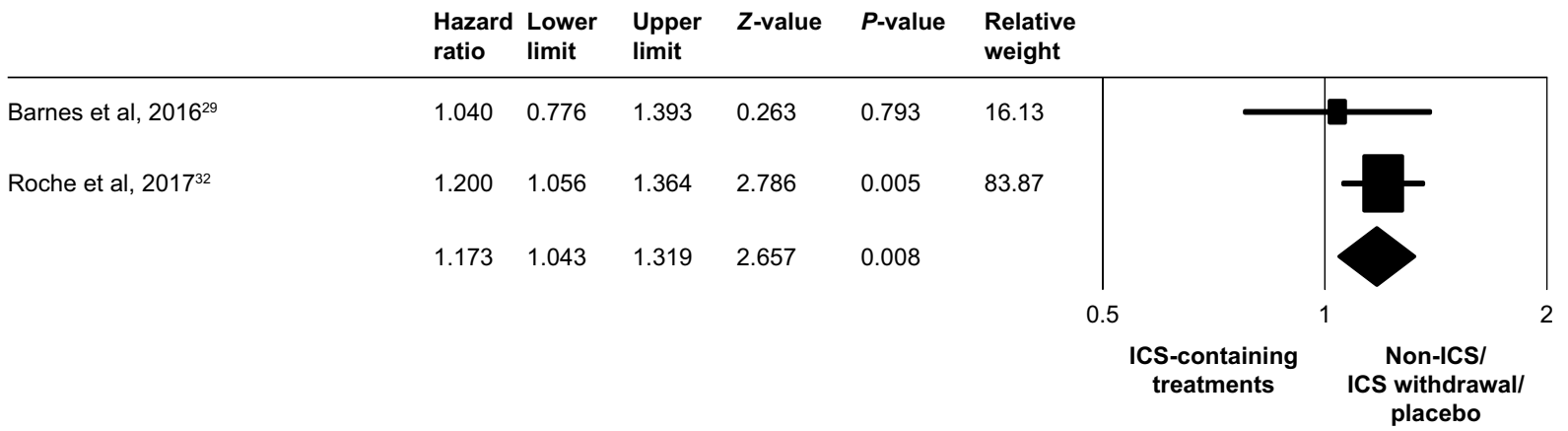

Figure 3 Forest plots of studies comparing the pooled hazard ratio for time-to-first moderate/severe exacerbation in patients with COPD receiving ICS-containing treatment or non-ICS/ICS withdrawal/placebo treatments by subgroup.

Note: (A) Eosinophil counts $<2 \%$ and (B) eosinophil counts $\geq 2 \%$.

Abbreviation: ICS, inhaled corticosteroid.

95\% CI, 1.043-1.319; $P=0.008)$, as shown in Figure 3B. Although numerous trials have confirmed the efficacy of ICS for the treatment of COPD, ICS may also increase the risk of pneumonia in patients with COPD. Analysis of two populations of five studies ${ }^{27,32}$ revealed that the risk of pneumonia events was significantly increased in the subgroup with eosinophil counts $\geq 2 \%$ with ICS-containing treatments (RR, 1.969; 95\% CI, 1.369-2.833; $P<0.001$ ), as shown in Figure 4A. There was no significant difference in the subgroup with eosinophil counts $<2 \%$ (RR, 1.291; 95\% CI, 0.888-1.879; $P=0.181$ ), as shown in Figure 4B.

\section{Discussion}

\section{Summary of main results}

We conducted a systematic review and meta-analysis to investigate the predictive role of baseline blood eosinophil counts as a biomarker of response to ICS in patients with moderate-to-very severe COPD. A total of five studies with 12,496 patients were used for analysis. The cutoff of $2 \%$ blood eosinophil counts was utilized to categorize patients in this study, and $60 \%$ of patients had $\geq 2 \%$ blood eosinophils at baseline. For patients with $\geq 2 \%$ blood eosinophils, the five studies provided inconsistent results when comparing the efficacy of ICS-containing regimens and non-ICS regimens/ ICS withdrawal/placebo treatments at reducing exacerbation risk. In the meanwhile, we excluded the patients treated with other anti-inflammatory agents such as oral steroid or phosphodiesterase type 4 inhibitors at the same time. Our meta-analysis showed a significantly decreased acute exacerbation risk in favor of ICS-containing treatments vs non-ICS/ICS withdrawal/placebo treatments for reducing COPD exacerbations in patients with $\geq 2 \%$ blood eosinophils (RR, $0.81 ; 95 \%$ CI, 0.67-0.99; $P=0.03$ ).

The characteristics of COPD include chronic inflammation and structural changes in the respiratory tract, which are mediated by inflammatory cells and a complex cytokine network. ${ }^{33,34}$ Neutrophils are the predominant cell type involved in airway inflammation in patients with COPD and account for $>70 \%$ of sputum cells. ${ }^{35,36}$ However, $~ 20 \%-40 \%$ of patients with stable COPD show elevated eosinophil levels $(>3 \%)$ in sputum. ${ }^{7}$ Furthermore, blood eosinophilia ( $\left.\geq 2 \%\right)$ has been reported in $50 \%-70 \%$ of patients with COPD. ${ }^{37}$ Eosinophils are multifunctional leukocytes characterized by the storage of cytotoxic basic proteins in secondary granules 
A

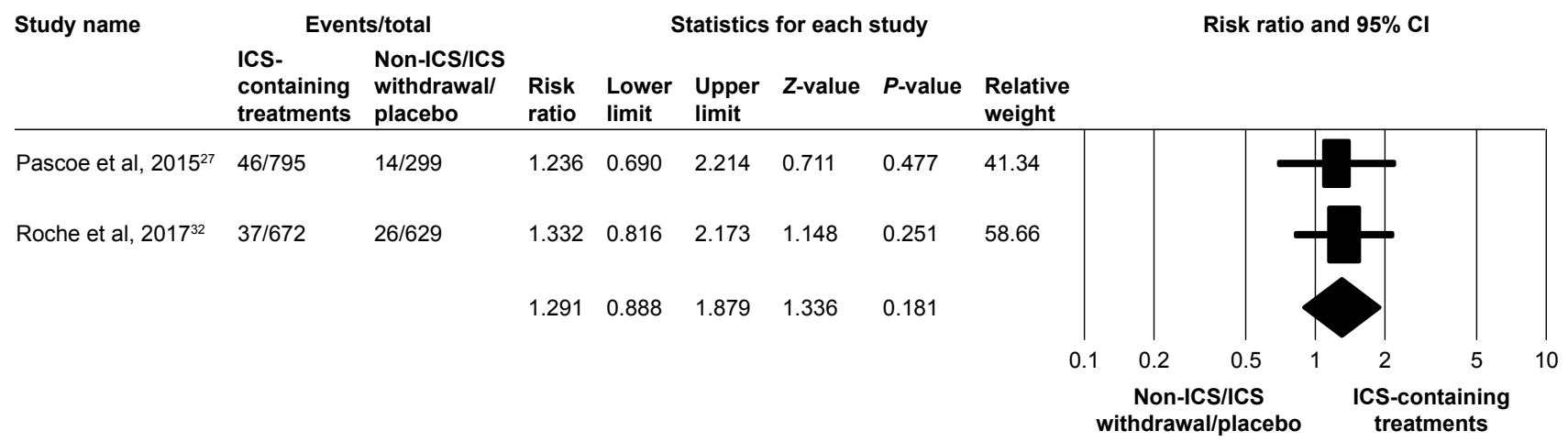

B

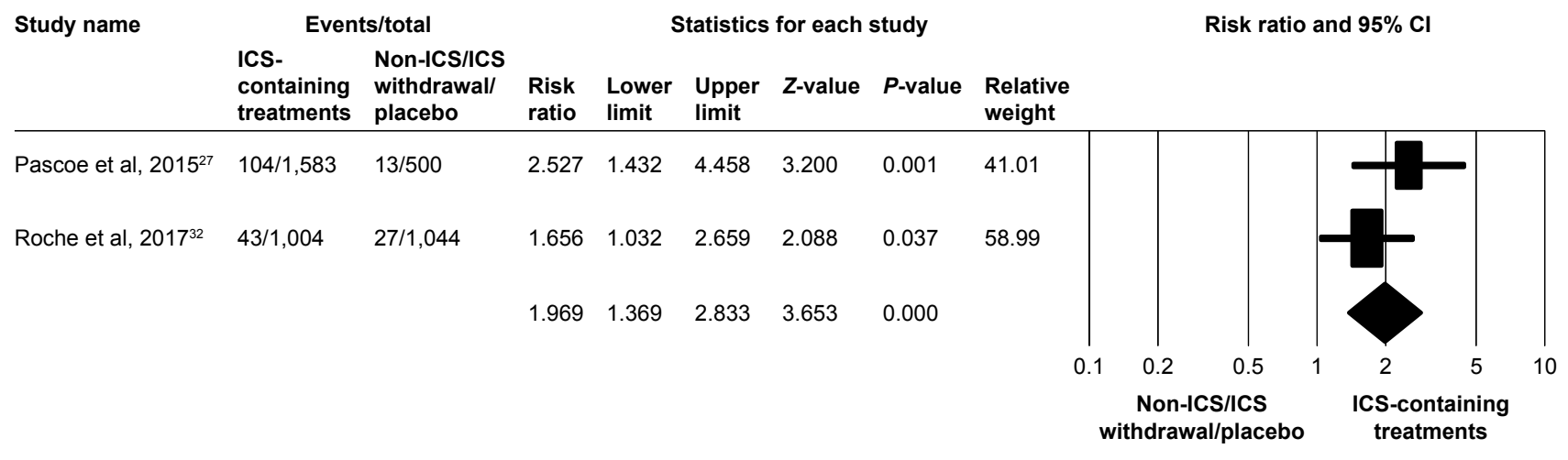

Figure 4 Forest plots of studies comparing the pooled relative risk of pneumonia events in patients with COPD receiving ICS-containing treatment or non-ICS/ICS withdrawal/placebo treatments by subgroup.

Note: (A) Eosinophil counts $<2 \%$ and (B) eosinophil counts $\geq 2 \%$.

Abbreviation: ICS, inhaled corticosteroid.

as well as the production of reactive oxygen species, lipid mediators, and cytokines. ${ }^{38,39}$ The release of cytotoxic basic proteins, reactive oxygen species, and lipid mediators is associated with damage to airway epithelial cells. ${ }^{7,39}$ During a COPD exacerbation, both absolute and relative eosinophil counts in sputum are significantly increased compared with those during the stable phase. ${ }^{36}$ Therefore, eosinophils may contribute to increased airway inflammation during acute exacerbations of COPD. ${ }^{36}$ Additionally, blood eosinophilia is associated with a higher risk of COPD exacerbation, ${ }^{40,41}$ which may lead to a decline in lung function ${ }^{7}$ and increased mortality. ${ }^{42}$

The molecular mechanisms for the anti-inflammatory activity of corticosteroids include repression of activated inflammatory genes, activation of anti-inflammatory genes, and posttranscriptional effects. ${ }^{43,44}$ At the cellular level, corticosteroids can inhibit the survival of eosinophils in the airways. ${ }^{43,45}$ Leigh et al reported that 4-week treatment with inhaled budesonide $(1,600 \mu \mathrm{g} /$ day $)$ normalized the sputum eosinophil counts in patients with COPD with sputum eosinophilia. ${ }^{12}$ In patients without sputum eosinophilia, the sputum eosinophil counts stayed within the normal range after budesonide treatment. ${ }^{12}$ Budesonide treatment did not significantly affect the sputum neutrophil counts of all enrolled patients. ${ }^{12}$ Similar results were observed in patients with COPD treated with a combination therapy of inhaled fluticasone $(200 \mu \mathrm{g} /$ day $)$ and salmeterol $(100 \mu \mathrm{g} /$ day $)$ for 2 months. ${ }^{46}$ In patients with sputum eosinophilia, the percentage of eosinophils in sputum significantly decreased from $8.9 \%$ to $1.6 \%(P=0.003)$ after treatment with inhaled fluticasone-salmeterol. ${ }^{46}$ In contrast, sputum neutrophils remained unchanged after fluticasone-salmeterol combination therapy. ${ }^{46}$ Based on currently available data, ICS can significantly suppress eosinophilic airway inflammation, but has less of an effect on neutrophilic airway inflammation, which predominates in COPD. ${ }^{12,46}$ There is some evidence suggesting that maintenance treatment with ICS is more effective in patients with COPD with higher eosinophil counts, with regards to reducing exacerbation frequency and improving lung function. ${ }^{27-31,47,48}$

Although asthma and COPD are two different chronic respiratory diseases, a significant proportion of patients 
aged $>40$ years present with overlapping conditions. ${ }^{49}$ These patients are categorized as having asthma-COPD overlap syndrome (ACOS). ${ }^{49} \mathrm{~A}$ joint project of the Global Initiative for Asthma and the Global initiative for chronic Obstructive Lung Disease (GOLD) provides the clinical description for ACOS:

ACOS is characterized by persistent airflow limitation with several features usually associated with asthma and several features usually associated with COPD. ACOS is therefore identified in clinical practice by the features that it shares with both asthma and COPD. ${ }^{49}$

However, there is no universally accepted definition of ACOS at present. Previous large-scale studies have revealed that the prevalence rates of ACOS in patients with COPD are between $5.6 \%$ and $55 \%$, depending on the diagnostic criteria applied. ${ }^{50-57}$ The mixed COPD-asthma phenotype is associated with more respiratory symptoms, increased risk of exacerbation and hospitalization, and worse health-related quality of life compared with the pure COPD phenotype. ${ }^{53,54,56,58,59}$ Regarding eosinophils, patients with ACOS show significantly higher sputum and blood eosinophil counts than those with pure COPD.${ }^{60} \mathrm{~A}$ blood eosinophil count $>5 \%$ was used as a minor criterion for defining ACOS in a cohort of Spanish patients with COPD. ${ }^{51}$

Several studies suggested that ACOS patients were more likely to benefit from ICS treatment because of sputum eosinophilia. ${ }^{52,60,61}$ Kitaguchi et al reported that patients with ACOS showed a significant increase in forced expiratory volume $1\left(\mathrm{FEV}_{1} ; 32.4 \%\right)$ than did those with pure COPD (12.8\%) after being treated with inhaled fluticasone propionate (400 $\mu \mathrm{g} / \mathrm{day})$ for $2-3$ months ${ }^{60}$ Moreover, a significant correlation was observed between the increase in $\mathrm{FEV}_{1}$ and sputum eosinophil counts. ${ }^{60}$ In a study conducted by Lee et al, the improvement in $\mathrm{FEV}_{1}$ was significantly greater in patients with ACOS $(240.2 \pm 33.5 \mathrm{~mL})$ than that in patients with pure COPD $(124.6 \pm 19.8 \mathrm{~mL})$ after 3 months of treatment with ICS+LABA (salmeterol $50 \mu \mathrm{g}$ /fluticasone $500 \mu \mathrm{g}$ or formoterol $9 \mu \mathrm{g} /$ budesonide $320 \mu \mathrm{g}$ twice daily). ${ }^{61}$ A Canadian longitudinal cohort study revealed that new use of ICS+LABA was associated with a modestly reduced risk of death or COPD hospitalization in patients with COPD compared with new use of LABA alone (HR, 0.92; 95\% CI, 0.88-0.96). ${ }^{52}$ A more pronounced reduction in risk was observed in the ACOS subgroup (HR, 0.84; 95\% CI, 0.77-0.91). ${ }^{52}$

Based on clinical evidence, the GOLD 2017 guidelines recommend ICS+LABA as the first-line treatment in patients with high blood eosinophil counts and/or ACOS. ${ }^{62}$ In a joint project by Global Initiative for Asthma and GOLD, ICS was considered as the initial treatment for ACOS patients, and add-on treatment with LABA and/or LAMA is also usually necessary. ${ }^{49}$

It is still debated whether high eosinophil levels in either sputum or blood are associated with a severe COPD allergic phenotype, including greater exacerbation frequency, and whether blood eosinophils are predictive of sputum eosinophils. Hastie et al reported that high concentrations of sputum eosinophils were a better biomarker than high concentrations of blood eosinophils to identify a patient subgroup with more severe disease, more frequent exacerbations, and increased emphysema by quantitative computer tomography. ${ }^{63}$ Further studies should be performed to demonstrate the roles of sputum or blood eosinophil counts in COPD.

The most commonly used cutoff point for blood eosinophil counts in previous studies was $2 \%^{27,29-32}$ because this level showed high sensitivity for identifying sputum eosinophilia of $\geq 3 \% .{ }^{10}$ However, our meta-analysis indicated that the $2 \%$ threshold may be too low to accurately identify the group of patients most likely to benefit from ICS treatment. In several studies, the choice of a cutoff point showing the best predictive ability of blood eosinophils was based on the analyses of treatment outcomes, such as COPD exacerbation rate, stratified by a number of possible blood eosinophil levels. ${ }^{28,31,47,48}$ In the NCT01009463 and NCT01017952 trials, there was a linear relationship between blood eosinophil count and the RR of annual exacerbation rate for fluticasone furoate-vilanterol vs vilanterol, and a blood eosinophil cutoff of $2.4 \%$ was used in the cluster analysis $(>2.4 \%$ blood eosinophils: RR, 0.68; 95\% CI, 0.58-0.79; blood eosinophil count $\leq 2.4 \%$ : RR, 0.94; 95\% CI, 0.80-1.11). ${ }^{47}$ Results of the WISDOM trial suggested that blood eosinophil counts of $\geq 4 \%$ or $\geq 300$ cells/ $\mu \mathrm{L}$ may identify patients with COPD requiring continuation treatment with ICS (triple therapy consisting of fluticasone propionate, salmeterol, and tiotropium). ${ }^{31}$ According to the post hoc analysis of the FORWARD trial, the greatest differences in COPD exacerbation rate (reduction: $46 \% ; P \leq 0.001$ ) and improvements in $\mathrm{FEV}_{1}$ (difference: 0.102; $P=0.001$ ) and St George's Respiratory Questionnaire for COPD score (difference: -5.9 ; $P \leq 0.001$ ) between dipropionate-formoterol fumarate and formoterol fumarate were observed in patents with blood eosinophil counts of $\geq 279.8$ cells $/ \mu \mathrm{L} .{ }^{28}$ A pooled analysis of the LANTERN and ILLUMINATE trials demonstrated that fluticasone-salmeterol was more effective than indacaterolglycopyrronium at reducing exacerbation risk in patients 
with COPD with blood eosinophil counts $>300$ cells $/ \mu \mathrm{L}$ (RR, 0.59). ${ }^{48}$

The optimal cutoff points of blood eosinophil counts $(2.4 \%-4 \%$ and $279.8-300$ cells $/ \mu \mathrm{L})$ obtained from the studies mentioned above ${ }^{28,31,47,48}$ might not represent the true predictive ability because of the implicit multiple comparisons with different possible cutoff points. Further randomized studies with a biomarker-stratified design should be performed in order to find the most appropriate cutoff point for blood eosinophils.

Since COPD is a highly heterogeneous disease and several molecular mechanisms are associated with corticosteroid resistance, ${ }^{43}$ the combination of blood eosinophil counts with other markers may achieve the best predictive accuracy in predicting treatment response to ICS. ${ }^{17}$ Cigarette smoking is not only the primary cause of COPD but also associated with a poor response to ICS. ${ }^{64}$ Various mechanisms may be involved in the development of resistance to ICS, in particular, HDAC2 dysfunction. ${ }^{6466}$ Peroxynitrite produced by the reaction of nitric oxide and superoxide anion from cigarette smoke may cause reduced HDAC2 activity and expression, which decreases the efficacy of ICS. ${ }^{65,66}$

A cluster analysis of the patients who may benefit more from fluticasone furoate-vilanterol vs vilanterol identified three separate clusters in 3,255 patients with smoking-related COPD from the NCT01009463 and NCT01017952 trials. ${ }^{47}$ Cluster 1 included patients with $>2.4 \%$ blood eosinophils $(\mathrm{n}=1,777,54.6 \%)$, cluster 2 included patients with $\leq 2.4 \%$ blood eosinophils and a smoking history of $\leq 46$ pack-years $(n=891,27.4 \%)$, and cluster 3 included patients with $\leq 2.4 \%$ blood eosinophils and a smoking history of $>46$ pack-years $(\mathrm{n}=587,18.0 \%)$. The RRs of annual exacerbation rates for fluticasone furoate-vilanterol vs vilanterol revealed that the greatest treatment effect of fluticasone furoate-vilanterol was found in cluster 1 (RR, 0.68; 95\% CI, 0.58-0.79). Patients in cluster 2 may also benefit from fluticasone furoate-vilanterol treatment (RR, 0.78 ; 95\% CI, 0.63-0.96); however, those in cluster 3 were considered to be non-responders to fluticasone furoate-vilanterol (RR, 1.22; 95\% CI, 0.94-1.58). Blood eosinophil count was the most important factor affecting the treatment response to fluticasone furoate-vilanterol, followed by smoking history. The impact of smoking history on ICS treatment in patients with COPD also warrants further investigation.

\section{Limitations of this study}

Our meta-analysis was limited to only five studies on the post hoc analyses of eight randomized trials. None of these trials were originally designed to assess the usefulness of blood eosinophils as a biomarker for predicting the response to ICS in patients with COPD. Heterogeneity in study design and patient populations was observed across the eight trials. Randomized withdrawal study design was only utilized in the WISDOM trial. ${ }^{31}$ The experimental and active comparator arms were somewhat heterogeneous among trials. The combination therapy of ICS+LABA or ICS+LABA+LAMA was studied in seven trials, ${ }^{27,30-32}$ and the results suggest that the therapeutic response to ICS may be influenced by LABA or LABA+LAMA to some degree. The FLAME trial recruited patients with moderate-to-very severe airflow limitation. ${ }^{32}$ Five trials involved patients with moderate-to-severe COPD $;{ }^{27,29,30}$ however, two trials involved patients with more severe disease (severe-to-very severe COPD). ${ }^{30,31}$ Patients without a history of exacerbations could only be enrolled in the SCO30002 trial, ${ }^{30}$ while patients who had never smoked were excluded from all trials. ${ }^{27,29,31,32,67-69}$ Therefore, our results may not be generalizable to real-world patients suitable for ICS therapy as recommended by the GOLD guidelines. ${ }^{62}$ The withdrawal rates in the ICS-containing treatment arms and active comparator/placebo arms were $18.3 \%-34.5 \%$ and $16.6 \%-41.7 \%$, respectively. $2,32,67-71$ The highest withdrawal rates $(34.5 \%$ in the fluticasone propionate-salmeterol group and $41.7 \%$ in the tiotropium group) were observed in the INSPIRE trial, which included patients with severe and very severe COPD.$^{69}$ In the INSPIRE, ${ }^{69}$ ISOLDE, ${ }^{70}$ and TRISTAN 66 trials, significantly higher proportions of patients in the active comparator or placebo arms failed to complete the study than did those in the ICS-containing arms. High withdrawal rates could lead to bias in the estimates of treatment effect because patients who completed the study may be healthier than the population at study entry.

A comprehensive assessment of the relationship between blood eosinophil counts and the treatment effects of ICS regimens is necessary. However, the meta-analysis of other efficacy parameters, such as time to first exacerbation, $\mathrm{FEV}_{1}$, St George's Respiratory Questionnaire for COPD total score, and mortality was not performed in this study because some of these data stratified by blood eosinophil counts were not presented in the five studies.

\section{Conclusion}

Our meta-analysis suggested a modest benefit from ICScontaining treatments vs non-ICS/ICS withdrawal/placebo treatments in reducing the annual rate of moderate/severe exacerbations in patients with COPD with $\geq 2 \%$ blood eosinophils at baseline. However, the incidence of pneumonia 
risk was also increased in patients with COPD with higher eosinophil counts who used ICS treatment. To be useful in clinical practice, further prospectively designed studies with prespecified criteria for blood eosinophil subgroups of patients with COPD are required to identify the best cutoff point for blood eosinophil count.

\section{Disclosure}

The author reports no conflicts of interest in this work.

\section{References}

1. Ferguson GT, Anzueto A, Fei R, Emmett A, Knobil K, Kalberg C. Effect of fluticasone propionate/salmeterol (250/25 microg) or salmeterol (50 microg) on COPD exacerbations. Respir Med. 2008;102(8): 1099-1108.

2. Dransfield MT, Bourbeau J, Jones PW, et al. Once-daily inhaled fluticasone furoate and vilanterol versus vilanterol only for prevention of exacerbations of COPD: two replicate double-blind, parallel-group, randomised controlled trials. Lancet Respir Med. 2013;1(3):210-223.

3. Szafranski W, Cukier A, Ramirez A, et al. Efficacy and safety of budesonide/formoterol in the management of chronic obstructive pulmonary disease. Eur Respir J. 2003;21(1):74-81.

4. Sharafkhaneh A, Southard JG, Goldman M, Uryniak T, Martin UJ. Effect of budesonide/formoterol pMDI on COPD exacerbations: a double-blind, randomized study. Respir Med. 2012;106(2):257-268.

5. Agarwal R, Aggarwal AN, Gupta D, Jindal SK. Inhaled corticosteroids vs placebo for preventing COPD exacerbations: a systematic review and metaregression of randomized controlled trials. Chest. 2010;137(2): 318-325

6. Suissa S. Number needed to treat in COPD: exacerbations versus pneumonias. Thorax. 2013;68(6):540-543.

7. Saha S, Brightling CE. Eosinophilic airway inflammation in COPD. Int J Chron Obstruct Pulmon Dis. 2006;1(1):39-47.

8. Brightling CE. Clinical applications of induced sputum. Chest. 2006; 129(5):1344-1348.

9. Singh D, Kolsum U, Brightling CE, et al. Eosinophilic inflammation in COPD: prevalence and clinical characteristics. Eur Respir J. 2014; 44(6):1697-1700.

10. Bafadhel M, McKenna S, Terry S, et al. Acute exacerbations of chronic obstructive pulmonary disease: identification of biologic clusters and their biomarkers. Am J Respir Crit Care Med. 2011;184(6):662-671.

11. McDonald VM, Higgins I, Wood LG, Gibson PG. Multidimensional assessment and tailored interventions for COPD: respiratory utopia or common sense? Thorax. 2013;68(7):691-694.

12. Leigh R, Pizzichini MM, Morris MM, Maltais F, Hargreave FE, Pizzichini E. Stable COPD: predicting benefit from high-dose inhaled corticosteroid treatment. Eur Respir J. 2006;27(5):964-971.

13. Brightling CE, Monteiro W, Ward R, et al. Sputum eosinophilia and shortterm response to prednisolone in chronic obstructive pulmonary disease: a randomised controlled trial. Lancet. 2000;356(9240):1480-1485.

14. Brightling CE, McKenna S, Hargadon B, et al. Sputum eosinophilia and the short term response to inhaled mometasone in chronic obstructive pulmonary disease. Thorax. 2005;60(3):193-198.

15. Pizzichini E, Pizzichini MM, Gibson P, et al. Sputum eosinophilia predicts benefit from prednisone in smokers with chronic obstructive bronchitis. Am J Respir Crit Care Med. 1998;158(5 Pt 1):1511-1517.

16. Pavord ID, Bafadhel M. Exhaled nitric oxide and blood eosinophilia: independent markers of preventable risk. J Allergy Clin Immunol. 2013; 132(4):828-829.

17. Baines KJ, Pavord ID, Gibson PG. The role of biomarkers in the management of airways disease. Int J Tuberc Lung Dis. 2014;18(11): 1264-1268.
18. Pavord ID, Gibson PG. Inflammometry: the current state of play. Thorax. 2012;67(3):191-192.

19. Yap E, Chua WM, Jayaram L, Zeng I, Vandal AC, Garrett J. Can we predict sputum eosinophilia from clinical assessment in patients referred to an adult asthma clinic? Intern Med J. 2013;43(1):46-52.

20. Korevaar DA, Westerhof GA, Wang J, et al. Diagnostic accuracy of minimally invasive markers for detection of airway eosinophilia in asthma: a systematic review and meta-analysis. Lancet Respir Med. 2015; 3(4):290-300.

21. Westerhof GA, Korevaar DA, Amelink M, et al. Biomarkers to identify sputum eosinophilia in different adult asthma phenotypes. Eur Respir J. 2015;46(3):688-696.

22. Zhang XY, Simpson JL, Powell H, et al. Full blood count parameters for the detection of asthma inflammatory phenotypes. Clin Exp Allergy. 2014;44(9):1137-1145.

23. Fowler SJ, Tavernier G, Niven R. High blood eosinophil counts predict sputum eosinophilia in patients with severe asthma. $J$ Allergy Clin Immunol. 2015;135(3):822-824.

24. Wagener AH, de Nijs SB, Lutter R, et al. External validation of blood eosinophils in asthma. Thorax. 2015;70(2):115-120.

25. Eltboli O, Mistry V, Barker B, Brightling CE. Relationship between blood and bronchial submucosal eosinophilia and reticular basement membrane thickening in chronic obstructive pulmonary disease. Respirology. 2015;20(4):667-670.

26. Bafadhel M, McKenna S, Terry S, et al. Blood eosinophils to direct corticosteroid treatment of exacerbations of chronic obstructive pulmonary disease: a randomized placebo-controlled trial. Am J Respir Crit Care Med. 2012;186(1):48-55

27. Pascoe S, Locantore N, Dransfield MT, Barnes NC, Pavord ID. Blood eosinophil counts, exacerbations, and response to the addition of inhaled fluticasone furoate to vilanterol in patients with chronic obstructive pulmonary disease: a secondary analysis of data from two parallel randomised controlled trials. Lancet Respir Med. 2015;3(6):435-442.

28. Siddiqui SH, Guasconi A, Vestbo J, et al. Blood eosinophils: a biomarker of response to extrafine beclomethasone/formoterol in chronic obstructive pulmonary disease. Am J Respir Crit Care Med. 2015;192(4): $523-525$.

29. Barnes NC, Sharma R, Lettis S, Calverley PM. Blood eosinophils as a marker of response to inhaled corticosteroids in COPD. Eur Respir J. 2016;47(5):1374-1382.

30. Pavord ID, Lettis S, Locantore N, et al. Blood eosinophils and inhaled corticosteroid/long-acting $\beta-2$ agonist efficacy in COPD. Thorax. 2016;71(2):118-125.

31. Watz H, Tetzlaff K, Wouters EF, et al. Blood eosinophil count and exacerbations in severe chronic obstructive pulmonary disease after withdrawal of inhaled corticosteroids: a post-hoc analysis of the WISDOM trial. Lancet Respir Med. 2016;4(5):390-398.

32. Roche N, Chapman KR, Vogelmeier CF, et al. Blood eosinophils and response to maintenance chronic obstructive pulmonary disease treatment. Data from the FLAME trial. Am J Respir Crit Care Med. 2017; 195(9):1189-1197.

33. Barnes PJ. The cytokine network in chronic obstructive pulmonary disease. Am J Respir Cell Mol Biol. 2009;41(6):631-638.

34. Barnes PJ. Immunology of asthma and chronic obstructive pulmonary disease. Nat Rev Immunol. 2008;8(3):183-192.

35. Bathoorn E, Liesker JJ, Postma DS, et al. Change in inflammation in out-patient COPD patients from stable phase to a subsequent exacerbation. Int J Chron Obstruct Pulmon Dis. 2009;4:101-109.

36. Fujimoto K, Yasuo M, Urushibata K, Hanaoka M, Koizumi T, Kubo K. Airway inflammation during stable and acutely exacerbated chronic obstructive pulmonary disease. Eur Respir J. 2005;25(4): 640-646.

37. Iyer AS, Dransfield MT. Serum eosinophils as a COPD biomarker: ready for prime time? Lancet Respir Med. 2016;4(5):341-343.

38. George L, Brightling CE. Eosinophilic airway inflammation: role in asthma and chronic obstructive pulmonary disease. Ther Adv Chronic Dis. 2016;7(1):34-51. 
39. Nixon J, Newbold P, Mustelin T, Anderson GP, Kolbeck R. Monoclonal antibody therapy for the treatment of asthma and chronic obstructive pulmonary disease with eosinophilic inflammation. Pharmacol Ther. 2017;169:57-77.

40. Hasegawa K, Camargo CA. Prevalence of blood eosinophilia in hospitalized patients with acute exacerbation of COPD. Respirology. 2016; 21(4):761-764.

41. Price D, Rigazio A, Postma D, et al. Blood eosinophilia and the number of exacerbations in COPD patients. Eur Respir J. 2014;44 (Suppl 58):4416.

42. Hospers JJ, Schouten JP, Weiss ST, Postma DS, Rijcken B. Eosinophilia is associated with increased all-cause mortality after a follow-up of 30 years in a general population sample. Epidemiology. 2000;11(3): 261-268.

43. Barnes PJ. Glucocorticosteroids: current and future directions. $\mathrm{Br} \mathrm{J}$ Pharmacol. 2011;163(1):29-43.

44. Barnes PJ. Inhaled corticosteroids. Pharmaceuticals. 2010;3(3): 514-540.

45. Meagher LC, Cousin JM, Seckl JR, Haslett C. Opposing effects of glucocorticoids on the rate of apoptosis in neutrophilic and eosinophilic granulocytes. J Immunol. 1996;156(11):4422-4428.

46. Perng DW, Wu CC, Su KC, Lee YC, Perng RP, Tao CW. Inhaled fluticasone and salmeterol suppress eosinophilic airway inflammation in chronic obstructive pulmonary disease: relations with lung function and bronchodilator reversibility. Lung. 2006;184(4):217-222.

47. Hinds DR, Disantostefano RL, Le HV, Pascoe S. Identification of responders to inhaled corticosteroids in a chronic obstructive pulmonary disease population using cluster analysis. BMJ Open. 2016;6(6): e010099.

48. Wedzicha JA, Price D, Mezzi K, Fogel R, Banerji D. QVA149 compared with salmeterol/fluticasone (SFC) on exacerbations and its correlation with baseline blood eosinophils: a pooled analysis of LANTERN and ILLUMINATE. Eur Respir J. 2015;46(Suppl 59):PA1005.

49. Global Initiative for Asthma (GINA) and Global Initiative for Chronic Obstructive Lung Disease (GOLD) [webpage on the Internet]. Diagnosis of diseases of chronic airway limitation: asthma, COD and asthmaCOPD overlap syndrome (ACOS) [updated 2015]. Available from: http://goldcopd.org/asthma-copd-asthma-copd-overlap-syndrome/. Accessed April 27, 2017.

50. Baarnes CB, Kjeldgaard P, Nielsen M, Miravitlles M, Ulrik CS. Identifying possible asthma-COPD overlap syndrome in patients with a new diagnosis of COPD in primary care. NPJ Prim Care Respir Med. 2017; 27:16084.

51. Cosio BG, Soriano JB, López-Campos JL, etal. Defining the asthma-COPD overlap syndrome in a COPD cohort. Chest. 2016;149(1):45-52.

52. Gershon AS, Campitelli MA, Croxford R, et al. Combination longacting $\beta$-agonists and inhaled corticosteroids compared with long-acting $\beta$-agonists alone in older adults with chronic obstructive pulmonary disease. JAMA. 2014;312(11):1114-1121.

53. Hardin M, Cho M, McDonald ML, et al. The clinical and genetic features of COPD-asthma overlap syndrome. Eur Respir J. 2014;44(2): 341-350.

54. Hardin M, Silverman EK, Barr RG, et al. The clinical features of the overlap between COPD and asthma. Respir Res. 2011;12:127.

55. Marsh SE, Travers J, Weatherall M, et al. Proportional classifications of COPD phenotypes. Thorax. 2008;63(9):761-767.
56. Menezes AMB, Montes de Oca M, Pérez-Padilla R, et al. Increased risk of exacerbation and hospitalization in subjects with an overlap phenotype: COPD-asthma. Chest. 2014;145(2):297-304.

57. Rhee CK, Yoon HK, Yoo KH, et al. Medical utilization and cost in patients with overlap syndrome of chronic obstructive pulmonary disease and asthma. COPD. 2014;11(2):163-170.

58. Kauppi P, Kupiainen H, Lindqvist A, et al. Overlap syndrome of asthma and COPD predicts low quality of life. J Asthma. 2011;48(3): 279-285.

59. Miravitlles M, Soriano JB, Ancochea J, et al. Characterisation of the overlap COPD-asthma phenotype. Focus on physical activity and health status. Respir Med. 2013;107(7):1053-1060.

60. Kitaguchi Y, Komatsu Y, Fujimoto K, Hanaoka M, Kubo K. Sputum eosinophilia can predict responsiveness to inhaled corticosteroid treatment in patients with overlap syndrome of COPD and asthma. Int $J$ Chron Obstruct Pulmon Dis. 2012;7:283-289.

61. Lee SY, Park HY, Kim EK, et al. Combination therapy of inhaled steroids and long-acting beta2-agonists in asthma-COPD overlap syndrome. Int J Chron Obstruct Pulmon Dis. 2016;11:2797-2803.

62. Vogelmeier CF, Criner GJ, Martinez FJ, et al. Global strategy for the diagnosis, management, and prevention of chronic obstructive lung disease 2017 report. GOLD executive summary. Am J Respir Crit Care Med. 2017;195(5):557-582

63. Hastie AT, Martinez FJ, Curtis JL, et al. Association of sputum and blood eosinophil concentrations with clinical measures of COPD severity: an analysis of the SPIROMICS cohort. Lancet Respir Med. 2017;5(12):956-967.

64. Ito K, Lim S, Caramori G, Chung KF, Barnes PJ, Adcock IM. Cigarette smoking reduces histone deacetylase 2 expression, enhances cytokine expression, and inhibits glucocorticoid actions in alveolar macrophages. FASEB J. 2001;15(6):1110-1112.

65. Barnes PJ, Ito K, Adcock IM. Corticosteroid resistance in chronic obstructive pulmonary disease: inactivation of histone deacetylase. Lancet. 2004;363(9410):731-733.

66. Tamimi A, Serdarevic D, Hanania NA. The effects of cigarette smoke on airway inflammation in asthma and COPD: therapeutic implications. Respir Med. 2012;106(3):319-328.

67. Calverley P, Pauwels R, Vestbo J, et al. For TRial of Inhaled STeroids ANd long-acting beta2 agonists study group. Combined salmeterol and fluticasone in the treatment of chronic obstructive pulmonary disease: a randomised controlled trial. Lancet. 2003;361(9356):449-456.

68. GlaxoSmithKline. Clinical study register. SFCT 01/SCO30002. Available from: http://www.gsk-clinicalstudyregister.com/files/pdf/23674. pdf. Accessed April 6, 2017.

69. Wedzicha JA, Calverley PM, Seemungal TA, et al. The prevention of chronic obstructive pulmonary disease exacerbations by salmeterol/ fluticasone propionate or tiotropium bromide. Am J Respir Crit Care Med. 2008;177(1):19-26.

70. Burge PS, Calverley PM, Jones PW, Spencer S, Anderson JA, Maslen TK. Randomised, double blind, placebo controlled study of fluticasone propionate in patients with moderate to severe chronic obstructive pulmonary disease: the ISOLDE trial. BMJ. 2000;320(7245): 1297-1303.

71. Magnussen H, Disse B, Rodriguez-Roisin R, et al. Withdrawal of inhaled glucocorticoids and exacerbations of COPD. N Engl J Med. 2014; 371(14):1285-1294.
International Journal of COPD

\section{Publish your work in this journal}

The International Journal of COPD is an international, peer-reviewed journal of therapeutics and pharmacology focusing on concise rapid reporting of clinical studies and reviews in COPD. Special focus is given to the pathophysiological processes underlying the disease, intervention programs, patient focused education, and self management protocols.

\section{Dovepress}

This journal is indexed on PubMed Central, MedLine and CAS. The manuscript management system is completely online and includes a very quick and fair peer-review system, which is all easy to use. Visit http://www.dovepress.com/testimonials.php to read real quotes from published authors. 